\title{
Lizards of the World: Natural History and Taxon Accounts
}

\author{
Gordon H. Rodda \\ Johns Hopkins University Press, ISBN 9781421438238 (hard cover), \\ 9781421438245 (ebook), pp 801.
}

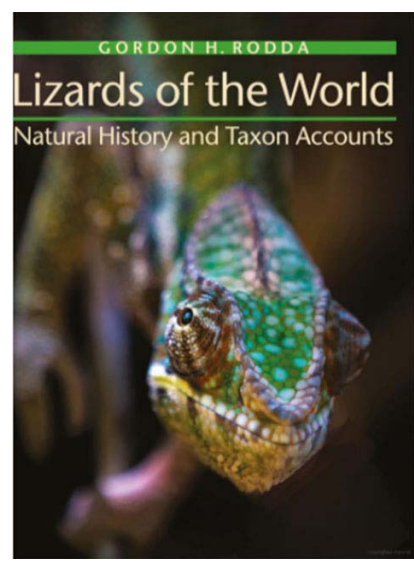

W hen I heard on the grapevine that Gordon Rodda was writing a book on the natural history of the world's 6,528 lizard species (the cut-off point for the count was May 2017) I thought "this is too big a task for one person, it can't be done". Well, it can.

Then the review copy landed on my doorstep a massive tome which of the books on my shelves is exceeded in weight only by Volume 1 of the concise edition of The Birds of the Western Palearctic. My first reaction was "what information can this contribute that I can't get free on the web from sites such as reptile-database"? Then I began reading, and it soon became apparent that the answer to this question is "a lot". In fact, this book isn't just physically big - it's intellectually overwhelming.

The core of this volume is Chapter 5, headed Taxon Accounts. It runs to 578 pages - nearly three quarters of the whole. This, like the rest of the book, is derived from a database which, as well as taxonomic information, includes 170 "most important natural history attributes". This apparently took eight years to compile: the database has $1,109,760$ cells. The author decided that the most convenient way to arrange the material is alphabetically by genus, because it's so much easier than needing to know a species' place in the taxonomic hierarchy before you can find it. So the chapter starts with Ablepharus and finishes with Zygaspis. Amphisbaenids and Sphenodon are included as lizards, and whatever one may feel about the appropriateness of this, it does aid comparisons. Did you know, for example, that Sphenodon punctatus has the highest biomass density of any lizard as defined here? Each genus has on average about half a page of text describing its biology, and the individual species are listed as boxed tables, with two lines per species. These are in a standard format: to give an idea of what information is available, the box for Podarcis muralis (chosen by me as a species with which I'm very familiar) looks like this. I have made a few small changes for clarity.

muralis Common wall lizard Europe diurnal omnivore 624.50 refugia-anchored ground lizard
The numbers are mean snout-vent length and body mass, the dietary and behaviour categories are defined in Chapters 1 and 4. Note that there is no information about thermoregulation; this is dealt with in the genus accounts, in this case the relevant entry reads "Fifty-two percent (v.25 \%) bask directly, and their mean active body temperature is average for lacertids (33.2 ${ }^{\circ} \mathrm{C}$ v $\left.33.3^{\circ} \mathrm{C}\right)$ ".

Podarcis muralis features specifically twice in the text relating to the genus. The first is "At least five species show a pattern of high moves per minute, while showing a percentile for time spent moving that is at least twenty percentiles lower... muralis $(95 / 68) \ldots$ but the general pattern suggests that there is a component to the movement of Podarcis that accentuates MPM over PTM; apparently they dart very expeditiously or for very short distances". The second is "the species' means (for biomass density) range from $0.3 \mathrm{~kg} / \mathrm{ha}$ (muralis) to 15.9 $\mathrm{kg} / \mathrm{ha}$ (lilfordi, siculus)". These short quotations illustrate features which are a major strength throughout the chapter - an attention to detail and quantification of statements, comparisons and comparative variables (such as "small" or "relatively large") whenever this is possible.

The database that I referred to above makes it possible to find correlations between species, states and variables, and Chapter 3 - at 62 pages, the second longest in the book does just this. I cannot, in a short review, begin to do justice to the richness of this material. Correlation is, of course, only suggestive of causation: so here is enough data-derived speculation to keep an army of researchers busy for years. If this were the only chapter in the book, it would still have immense value.

I loved the first sentence of Chapter 4 - "Lizard ecologists may have been misled by endotherm envy": this book isn't all just turgid scientific prose. What the chapter is about is trying to find a classification for life-style characteristics of lizards - the author calls them "ecological business models" - because these are needed for the database. There are 14 of them. Some, like "giant herbivore" or "glider", are relatively straightforward. Others have an element of arbitrariness. I would be hard put, for example, to find the boundary between "refugia-anchored diurnal ground lizard" (which is how he classifies Podarcis muralis) and "wide-ranging chemosensor".

The remaining two chapters are "housekeeping". Chapter 1 is an Introduction which also includes an account of the methods employed in compiling and using the database, and definitions of terms used in the book. Chapter 2 is titled 
"What are lizards?" and its 13 pages are a short overview of the characteristics of lizards as a whole.

The first words of the book succinctly describe its aims: "I wish to describe for you the natural histories of all lizards. For example... I describe the environment in which each species lives, what it eats and how it reproduces. I do not help you to identify lizard species or distinguish higher taxa... nor do I report the evolutionary history of lizard species...". Does the book succeed in achieving these aims? The answer is emphatically "yes", with the proviso that it cannot, of course, give full details for all of the facts on which generalisations are made, nor can it give literature citations for every statement. This isn't a criticism - just a comment on what isn't possible within the bounds of a single volume which deals with more than six thousand species of animals. Given its size and scope, it's remarkably free from errors, and the publishers have done justice to the importance of the material in the quality of production. It must be becoming apparent by now that all of this won't come cheaply, and of course it doesn't: the hardback version costs $f 111$. Although this is an eyewatering sum, it's actually quite modest by the standards of book-production in 2020 .
I finish with a speculation. This book is going to be of huge value to lizard ecologists for a long time to come. Who will rise to the challenge of doing the same thing for the snakes of the world?...

\section{ROGER AVERY}

7 Bishops Avenue, Bishopsteignton, Devon, TQ14 9RE, UK (formerly School of Biological Sciences, Bristol University) Email: roger.avery1@btinternet.com 